\title{
Clinical Course of Untreated and Treated Chronic Hepatitis B in Pregnant Patients: A Prospective Study
}

\author{
Yasemin NADIR ${ }^{1}$, Ayse BATIREL ${ }^{1}$, Ayse Yasemin KARAGEYIM KARSIDAG ${ }^{2}$, Fatma KAYA NARTER ${ }^{3}$, \\ Ahmet NADIR ${ }^{4}$ \\ Istanbul, Turkey
}

ABSTRACT

OBJECTIVE: Implementation of strategies to prevent vertical transmission is highly important steps in reducing the global burden of chronic hepatitis $\mathrm{B}$. We conducted this prospective study to observe the clinical course and outcomes of untreated and treated HBV in pregnant.

STUDY DESIGN: HBsAg-positive pregnants were prospectively enrolled from 2013 to 2016 and antiviral therapy was administered to eligible patients. Pregnancy and neonatal outcomes were determined in the treated $(n=29)$ and untreated group $(n=136)$. Active-passive immunoprophylaxis was administered to infants and they were tested for HBsAg.

RESULTS: The risk factors for transmission (HBeAg positivity, history of previously-born HBsAg-positive child) were significantly higher in the treated group. All participants under treatment had sufficient viral suppression. Half of the pregnant women for whom the treatment was withheld at the postpartum period, experienced increased viral load. The treated group had significantly higher pre- and postpartum alanine aminotransferase levels more than the untreated group, although there were no significant differences in other biochemical parameters. There were no significant differences regarding fetal outcomes between the two groups. All infants were HBsAg-negative at seven months postpartum.

CONCLUSION: While the untreated group included inactive carriers, there were more patients at risk for transmission of HBV to their offsprings in the treated group. Half of the pregnant women for whom the treatment was withheld at the postpartum period, experienced increased viral load. Antiviral therapy did not adversely affect the outcomes of infants. As a result, we successfully prevented perinatal HBV transmission by close monitoring of participant pregnant women and starting antiviral therapy when needed.

Keywords: Chronic hepatitis B, Hepatic flare, Mother-to-child transmission, Perinatal transmission, Pregnancy

Gynecol Obstet Reprod Med 2021;27(3):221-226

1 University of Health Sciences, Kartal Dr. Lutfi Kirdar Research and Training Hospital Department of Infectious Diseases and Clinical Microbiology, Istanbul, Turkey

${ }^{2}$ University of Health Sciences Kartal Dr. Lutfi Kirdar Research and Training Hospital Department of Obstetrics and Gynecology, Istanbul, Turkey

${ }^{3}$ University of Health Sciences, Kartal Dr. Lutfi Kirdar Research and Training Hospital Department of Pediatrics, Division of Neonatology, Istanbul, Turkey

${ }^{4}$ University of Health Sciences, Kartal Dr. Lutfi Kirdar Research and Training Hospital Department of Family Medicine. Istanbul, Turkey

Address of Correspondence: Yasemin Nadir Sandikli Public Hospital, 03510 Sandikli, Afyonkarahisar, Turkey dryaseminz@gmail.com

Submitted for Publication: 13.03.2020 Revised for Publication: 09.04.2020 Accepted for Publication: 02.05.0.2020 Online Published: 10.12.2021

ORCID IDs of the authors: YN: 0000-0003-1346-4579,

$A B$ : 0000-0002-6005-636X, AYKK: 0000-0003-2282-2788,

FKN: 0000-0001-6858-790X, AN: 0000-0001-8871-8591

\begin{tabular}{c|c}
\hline Quick Response Code: & Access this article online \\
\cline { 2 - 2 } & Website: www.gorm.com.tr \\
& e- mail: info@gorm.com.tr \\
\hline
\end{tabular}

How to cite this article: Nadir Y. Batirel A. Karageyim Karsidag AY. Kaya Narter F. Nadir A. Clinical Course of Untreated and Treated Chronic Hepatitis B in Pregnant Patients: A Prospective Study Gynecol Obstet Reprod Med 2021;27(3):221-226

\section{Introduction}

Accurate management of chronic hepatitis B (CHB) during pregnancy and implementation of strategies to prevent vertical transmission is a highly important step in reducing the global burden of CHB (1). The prevention of mother-to-child transmission (MTCT) is based on the combination of active and passive immunization of the newborn. The main risk factor of MTCT despite immunoprophylaxis is being the offspring of hepatitis $\mathrm{B}$ e antigen-positive and highly viremic mother (2). Thus, antiviral therapy in pregnant women is suggested with an HBV DNA level of $>200000 \mathrm{IU} / \mathrm{mL}$ (i.e.: 1 million copies $/ \mathrm{mL}$ ). According to guidelines' recommendations, antiviral therapy should be started at 28-32 weeks of gestation and continued for up to 12 weeks after delivery $(3,4)$. Most studies show that tenofovir or telbivudine during pregnancy may be safe and effective in preventing MTCT (5). We conducted this prospective study to observe the clinical course and features of untreated and treated CHB pregnant women, explore the differences between two groups in terms of laboratory parameters and their newborns' characteristics. 


\section{Material and Method}

1. Study Design: Hepatitis B virus (HBV)-infected pregnant women were prospectively enrolled at the University of Health Sciences- Kartal Dr. Lutfi Kirdar Research and Training Hospital, from December 2013 to May 2016. All recruited participants in this study fulfilled the following criteria: (a) pregnant women aged $\geq 18$ years (b) being HBsAgpositive $(+)$, (c) having no evidence of liver cirrhosis; (d) agreement to participate (all patients signed informed consent forms before screening). Our study was conducted in accordance with the principles of the Declaration of Helsinki and has been approved by the Institutional Review Board (Ethics board approval number is 89513307/1009/213; Registered Date 12.19.2013.)

2. Screening of participants: Pregnancy and neonatal outcomes that we studied were: risk factors for MTCT (HBeAg positivity and history of previously $\mathrm{HBsAg}(+)$ child), high viremia (HBV-DNA levels above 200,000 IU/ml), hepatic flare (an increase of ALT levels to 5 times the upper limit of normal level), full-term delivery, preterm delivery ( $<37$ gestational weeks), post-term delivery ( $>40$ gestational weeks), miscarriage (loss of a baby $<20$ th week), live birth, way of delivery (C-section/ Normal birth), low birth weight (LBW, $<2500 \mathrm{~g}$ ), high birth weight (HBW >4000), detection of HBsAg at seven months of age were collected.

3. Data Analyses: In this study, we used LH780 (Beckman Coulter, Mervue, Ireland) for complete blood count measurement and AU5800 (Beckman Coulter, Mervue, Ireland) for biochemical tests. The upper limits of all biochemical test parameters were based on the reference limits that were determined by the Biochemistry Laboratory. Architect i2000 SR enzyme-linked immunosorbent assay (ELISA) was used for HBsAg, HBeAg, anti-HBe tests. Serum HBV DNA level was determined by Roche COBAS ${ }^{\circledR}$ TaqMan ${ }^{\circledR}$ (a real-time polymerase chain reaction assay) with the detectable level of 20 $\mathrm{IU} / \mathrm{ml}$ and upper limit of $>170.000 .000 \mathrm{IU} / \mathrm{mL}$. Statistical analyses were performed using SPSS 17.0 software (SPSS Inc., Chicago, IL, USA). Results were shown as means \pm standard deviation (SD). For categorical variables, the chi-square test was used for comparisons between the groups. For continuous variables, the Mann-Whitney U test was used for comparisons between the two groups. A p-value of less than 0.05 was considered statistically significant.

\section{Results}

In total, 167 pregnant women were screened from December 2013 to May 2016. After 2 patients were excluded for misdiagnosis of pregnancy, 165 participants were enrolled. Figure 1 summarizes the clinical follow-up of pregnant women in our study. Overall, the median age was 30.6 \pm 5.4 years and $15.8 \%(26 / 165)$ of patients were $\mathrm{HBeAg}$-positive. We categorized pregnant women into two groups; the treated group $[\mathrm{n}=29$; Patients that were initiated therapy $(\mathrm{n}=15)$ and patients that became pregnant under antiviral therapy $(n=14)]$ and the untreated group $(n=136)$. The differences between these two groups were summarized in table I and table II.

Most of the pregnant women in the untreated group were $\mathrm{HBeAg-negative} \mathrm{and} \mathrm{anti-HBe} \mathrm{positive.} \mathrm{Generally,} \mathrm{CHB} \mathrm{was}$ well-tolerated in this group. Postnatal alanine aminotransferase (ALT) levels were found to be significantly higher than prenatal levels.

During this study, we decided to initiate antiviral therapy to 15 pregnant women $(9.1 \%)$ according to our treatment protocol ( $\mathrm{n}=2$ due to hepatic flares during pregnancy, $\mathrm{n}=13$ due to high HBV viremia). The mean time of initiating antiviral therapy was $24.2 \pm 6.0$ weeks of gestation (initiation of treatment earlier than 24 weeks was due to hepatic flares). We administered either tenofovir disoproxil fumarate (TDF) $(n=11)$ or telbivudine (LTD) $(n=4)$ to pregnant women. All participants under treatment had sufficient viral suppression (HBV-DNA $<200.000 \mathrm{IU} / \mathrm{mL})$.

Treatment of twelve out of 15 patients was stopped in the first month of the postpartum period (we decided the termination time of the treatment together with the patient, considering the patient's medical condition) and increased postnatal HBV-DNA levels were detected in $\% 50(n=6 / 12)$ of these pregnancies and treatment was restarted (all viral load became normal during follow up).

Patients who became pregnant under treatment for CHB $(n=14)$ were followed-up (TDF: $n=7$, Entecavir: $n=2$, Lamivudine: $\mathrm{n}=5$ ) in the treated group. In the TDF group; two pregnant women had abortus (thus we continued antiviral treatment after abortion). Antiviral therapy was withheld in the remaining 12 patients in the first trimester of pregnancy during the organogenesis of the fetus and no hepatic flares occurred during the untreated period. However, increased HBVDNA levels were detected in $25 \%(n=3 / 12)$ of these pregnancies after withholding antiviral drugs during pregnancy, then treatment was reinitiated (all patients had sufficient viral suppression at prepartum period).

The postpartum hepatic flare occurred in two patients (one in the untreated, one in the treated group). In the untreated group, a patient had postpartum hepatic flare despite a low prepartum HBV-DNA level (335 IU/ml) and negative-HBeAg status. In the treated group, a pregnant had postpartum hepatic flare due to withheld TDF treatment immediately after delivery. Both patients' transaminase levels became normal spontaneously during follow-up.

During the study period, 97.6\% $(n=161)$ of pregnant women gave live birth and $2.4 \%(n=2$ in the untreated group, $\mathrm{n}=2$ in the TDF-treated group) of them had abortus. Also, newborns experienced some problems such as breech presen- 
tation $(n=3)$, congenital VSD $(n=1)$, congenital eyelid abnormalities $(n=1)$, neonatal resuscitation $(n=1)$, corpus callosum agenesis $(n=1), R h$ incompatibility $(n=1)$, neonatal hypoglycemia $(n=1)$. However, there were no significant differ- ences between the treated and untreated groups in terms of these problems. In the follow-up period, 133 infants became seven months old so they were tested for HBsAg. All were HBsAg negative.

Figure 1: Clinical follow-up of pregnant women

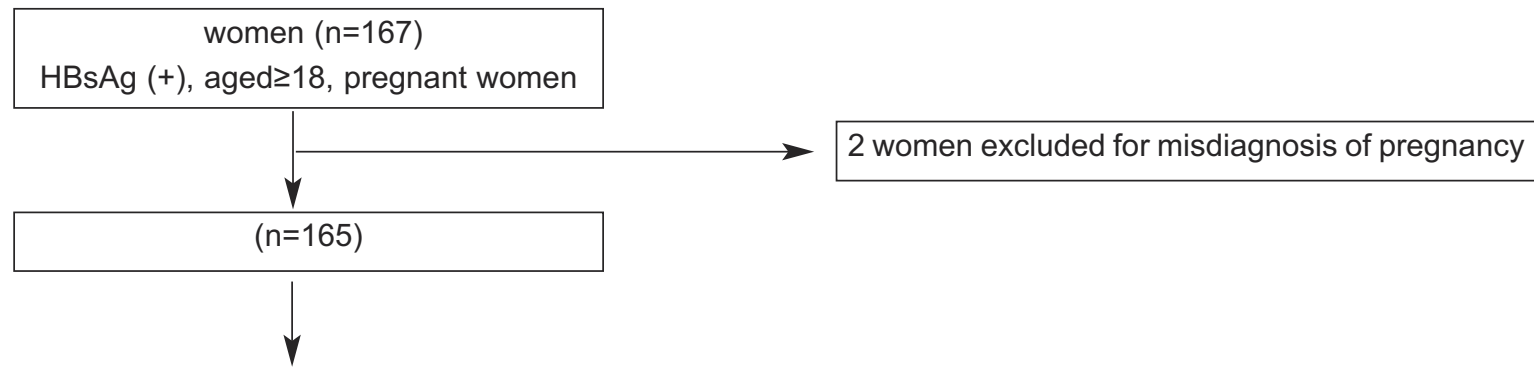

- HBsAg, anti Hbs, HbeAg, Anti HBe, HBV-DNA levels, ALT, AST, ALP, GGT, bilirubin, total protein, INR and complete blood count were tested at the first visit.

- HBV- DNA was monitored at the first, third trimester and at the first month of postpartum period.

- We determined a protocol for prenatal antiviral therapy to minimize fetal exposure to HBV, according to universal guidelines. We have started antiviral therapy to pregnant women who have high viremia $(>200.000 \mathrm{IU} / \mathrm{ml})$ and who have serious hepatic flare during pregnancy $(3,5)$.

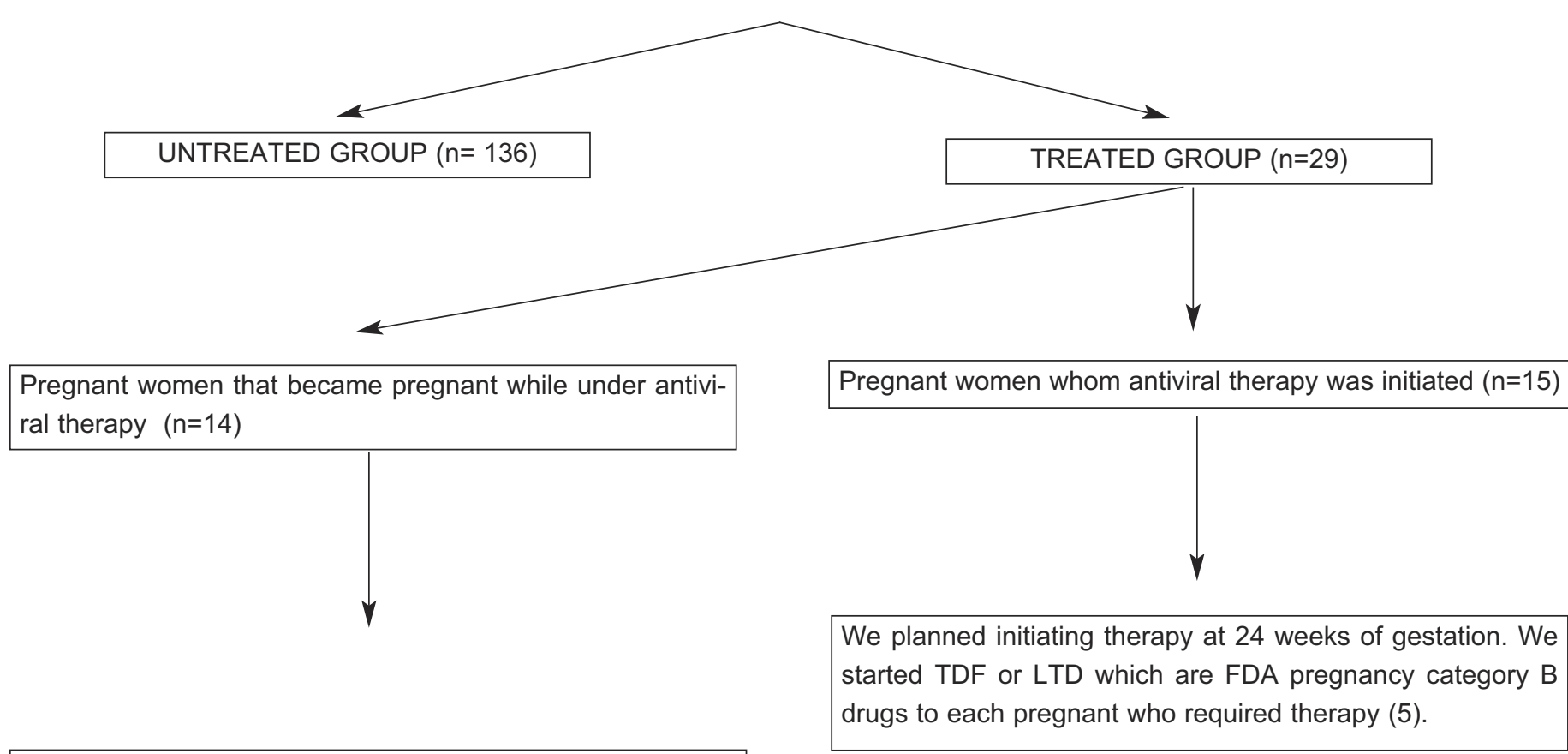

If the treatment was stopped at the first trimester and then there is an increase in the HBV-DNA level, therapy was reinitiated at the third trimester. (ETV was replaced with TDF, LAM was substituted for LTD)

- We recommended to continue therapy for up to 12 weeks after delivery and then we decided the termination time of the treatment together with patient, considering the patient's medical condition.

- All infants received $200 \mathrm{IU}$ of HBIG and $10 \mu \mathrm{g}$ of HBV vaccine intramuscularly within 12 hours after birth, and two additional vaccinations at 1 and 6 months of age. Serum HBsAg and Anti-HBs of these infants were tested at 7 months of age. 
Table I: Differences between the treated and the untreated groups

\begin{tabular}{|c|c|c|c|}
\hline & $\begin{array}{l}\text { Untreated } \\
\text { Group } \\
(n=136)\end{array}$ & $\begin{array}{l}\text { Treated } \\
\text { Group } \\
(n=29)\end{array}$ & $p$ \\
\hline & $\mathrm{n}(\%)$ & $\mathrm{n}(\%)$ & \\
\hline \multicolumn{4}{|l|}{ Age group (n=165) } \\
\hline 20-29 years old & $56(41.2)$ & $12(41.4)$ & $0.145^{\star}$ \\
\hline 30-39 years old & $73(53.7)$ & $16(55.2)$ & \\
\hline$\geq 40$ years old & $7(5.1)$ & $1(3.4)$ & \\
\hline \multicolumn{4}{|l|}{ HBeAg (n=151) } \\
\hline Negative & $126(96.9)$ & $4(3.1)$ & $<0.001^{*}$ \\
\hline Positive & $7(33.3)$ & $14(66.7)$ & \\
\hline \multicolumn{4}{|l|}{ Previously } \\
\hline \multicolumn{4}{|l|}{$\begin{array}{l}\text { HBsAg-positive child } \\
(n=128)\end{array}$} \\
\hline No & $110(90.9)$ & $11(9.1)$ & $0.004^{*}$ \\
\hline Yes & $3(42.9)$ & $4(51.1)$ & \\
\hline \multicolumn{4}{|l|}{ Increased postpartum } \\
\hline \multicolumn{4}{|l|}{$\begin{array}{l}\text { HBV DNA levels } \\
(n=124)\end{array}$} \\
\hline No & $70(92.1)$ & $6(7.9)$ & $0.128^{* *}$ \\
\hline Yes & $39(81.3)$ & $9(18.8)$ & \\
\hline $\begin{array}{l}\text { Postpartum hepatic flare } \\
(n=2)\end{array}$ & $1(50,0)$ & $1(50.0)$ & $0.421^{*}$ \\
\hline \multicolumn{4}{|l|}{$\begin{array}{l}\text { Status of pregnancy } \\
(n=165)\end{array}$} \\
\hline Miscarriage & $2(50.0)$ & $2(50.0)$ & $0.226^{*}$ \\
\hline Live Birth & $134(83.2)$ & $27(16.7)$ & \\
\hline \multicolumn{4}{|l|}{$\begin{array}{l}\text { Type of delivery } \\
(n=131)\end{array}$} \\
\hline \multicolumn{4}{|l|}{ Spontaneous vaginal } \\
\hline $\mathrm{C} / \mathrm{S}$ & $68(80.0)$ & $17(20.0)$ & \\
\hline \multicolumn{4}{|l|}{$\begin{array}{l}\text { Weight of newborns } \\
(n=131)\end{array}$} \\
\hline Normal & $95(82.6)$ & $20(17.4)$ & $0.021^{*}$ \\
\hline Low Birth Weight & $5(100)$ & $0(0)$ & \\
\hline High Birth Weight & $7(63.6)$ & $4(36.4)$ & \\
\hline \multicolumn{4}{|l|}{ Time of delivery $(n=131)$} \\
\hline Preterm delivery & $10(83.3)$ & $2(16.7)$ & $0.984^{* * *}$ \\
\hline Full-term delivery & $93(81.6)$ & $21(18.4)$ & \\
\hline Post-term delivery & $4(80.0)$ & $1(20.0)$ & \\
\hline
\end{tabular}

* Fisher's exact test, ${ }^{* *}$ Yates corrected chi-square test, ${ }^{* * *}$ Pearson chi-square test, ALT: Alanine aminotransferase, AST: Aspartate aminotransferase, C/S: Cesarean section

\section{Discussion}

Management of CHB during pregnancy and prevention of MTCT is a highly important precaution in reducing the global burden of $\mathrm{CHB}$ (6). In this study, we aimed to; observe the
Table II: Comparison of laboratory values between the treated and the untreated groups

\begin{tabular}{lccc}
\hline & $\begin{array}{c}\text { Untreated } \\
\text { group } \\
(\mathrm{n}=136)\end{array}$ & $\begin{array}{c}\text { Treated } \\
\text { group } \\
(\mathrm{n}=29)\end{array}$ & $p$ \\
\hline Albumin (mg/dL) & $3.8+0.5$ & $3.8+0.6$ & $0.927^{*}$ \\
Total bilirubin (mg/dL) & $0.4+0.3$ & $0.4+0.2$ & $0.397^{*}$ \\
ALP (U/L) & $87(26-223)$ & $87.9(16-179)$ & $0.591^{* *}$ \\
GGT (IU/L) & $14.4+7.2$ & $17.1+11.5$ & $0.437^{*}$ \\
Platelet 109/L & $224.2+65.6$ & $229+75.9$ & $0.933^{*}$ \\
INR & $0.8+0.2$ & $0.8+0.2$ & $0.604^{*}$ \\
Prenatal ALT (U/L) & $18(4-132)$ & $26(8-426)$ & $<0.001^{* *}$ \\
Postnatal ALT (U/L) & $22(9-1163)$ & $37.5(10-299)$ & $<0.001^{* *}$ \\
AST (U/L) & $22(6-981)$ & $25(14-132)$ & $0.013^{* *}$ \\
\hline
\end{tabular}

*Independent T-test, "*Mann-Whitney $U$ test, ALP: Alkaline phosphatase, ALT: Alanine aminotransferase, AST: Aspartate aminotransferase, GGT: Gamma-glutamyl transpeptidase, INR: International normalized ratio

clinical course and features of the untreated and treated chronic Hepatitis B in pregnant, explore the differences in the two groups in terms of laboratory values and their newborns' characteristics.

In accordance with numerous studies, our untreated group generally included inactive $\mathrm{HBsAg}$ carriers (HBeAg-negative, anti-HBe positive, low viral load). Also, we have found that the $\mathrm{HBeAg}$ positivity ratio is significantly higher in the treated group. HBeAg-positive and highly viremic mothers (as in our treated group) are the riskiest group for MTCT (7). In this study, no MTCT occurred in this group due to close follow- up and management. Some studies have reported that if perinatal transmission did occur in a prior pregnancy, then the risk of MTCT in the current pregnancy would likely be higher (8). Also, according to recent studies, starting antiviral therapy is recommended in women with a previous history of HBsAg-positive children regardless of the level of HBV DNA. Although this was not considered as a treatment indication in our study, we have found that the history of the previous $\mathrm{HbsAg-positive} \mathrm{child} \mathrm{ratio} \mathrm{was} \mathrm{significantly} \mathrm{higher} \mathrm{in}$ the treated group. Therefore, we should follow this group more carefully for MTCT.

In this study, there were no significant differences in terms of biochemical parameters between the treated and the untreated groups, except ALT levels. The treated group had significantly higher pre- and postpartum ALT levels more than the untreated group. In the untreated group, postnatal ALT levels were found to be significantly higher than prenatal levels. Similarly, in a study about HBV carriers, serum ALT levels were significantly higher than the control group (9). So even in the inactive carriers' group, there will be a deterioration of the liver histology in the postpartum period.

According to universal guidelines, antiviral therapy is rec- 
ommended to be started at 24-28 weeks of gestation for prevention of MTCT $(3,4)$ and we referred to those guidelines for the decision of treatment initiation time. We preferred TDF as initial therapy because of its antiviral potency and due to the data showing the reliability of its usage during pregnancy. A meta-analysis showed that TDF reduced the rates of MTCT with no increased risk for any adverse reactions or unfavorable maternal or fetal outcomes (10). In another study, tenofovir significantly reduced maternal viral load with a mean reduction of $3.64 \pm 0.9 \log 10 \mathrm{IU} / \mathrm{mL}$ and dramatically decreased the incidence of MTCT (11). Our study supports that data, sufficient viral suppression was achieved in pregnant women receiving either TDF or LTD and there no MTCT occurred. In the group receiving TDF, abortions could not be attributed to TDF because the other causes of abortion could not be investigated and ruled out. Similarly, in a study with HIV-infected pregnant women, spontaneous abortion occurred on TDF treatment, but it was not attributed to TDF, either (12). Thus, we need confirmation from studies involving longer-term follow-up of larger numbers of pregnant participants and ruling out other possible causes of spontaneous abortion.

Recent guidelines recommend continuing antiviral therapy for up to 12 weeks after delivery (4). Although all participants were sufficiently informed about these recommendations, most of the pregnant patients preferred to terminate the treatment immediately after delivery due to the concern of breastfeeding. Discontinuation of therapy requires serial monitoring of ALT and HBV DNA levels (13). By serial monitoring, we observed a high rate of an increase in postpartum HBV-DNA levels $(n=6 / 12,50 \%)$.

For patients who are already on treatment and become pregnant, the decision to withhold or continue therapy should be discussed considering disease stage and liver histology. For mothers with cirrhosis, treatment should be continued throughout pregnancy to prevent decompensation (14). There was no liver cirrhosis in our participants, so we decided whether to continue the treatment or not, together with both parents, by considering the health status of the pregnant and the fetus. Generally, antiviral therapy was withheld in the first trimester. In a study, eight out of twelve patients (66.7\%) had a viral rebound after stopping antiviral drugs during pregnancy and severe hepatitis flares were observed in six patients $(50 \%)(15)$. This study also showed that pregnant women with high pretreatment ALT levels or those treated less than one year before pregnancy had a high risk of hepatic flares. In our study, no hepatic flares occurred in this group and our viral rebound ratio was also lower than the study mentioned above $(\% 25)$. The probable cause may be that all patients were treated more than one year before pregnancy in our study (no data for pretreatment ALT).

Postpartum hepatic flare occurred both in the treated and the untreated group. It was remarkable that the patients' prenatal HBV-DNA levels were lower than $2000 \mathrm{IU} / \mathrm{mL}$ in the untreated group. In a study, it was shown that $29.6 \%(n=8)$ of $\mathrm{HBe} A g-$ negative participants had postpartum HBV reactivation, but only one of them had HBV-DNA level lower than $2000 \mathrm{IU} / \mathrm{mL}$ (16). Therefore, we had to monitor HBsAg-positive pregnant women closely for postpartum hepatic flare even if they had low prenatal HBV-DNA levels or were on antiviral therapy.

In a study, pregnant women were classified into two groups according to their viral load, and they found that gestational week at birth and birth weight in the immune active group were lower than those in group immune inactive group (17). When we examined the differences regarding fetal outcomes between the treated (immune active) and the untreated groups (immune inactive), there were no significant results for the type of delivery, the weight of the newborn, the status of pregnancy or the time of delivery. This may be due to the reduction of the viral load in the treated group in our study.

The problems that newborns experienced could not be attributed to antiviral therapy in our study. Similarly, recent studies showed that initiation of telbivudine or tenofovir treatment during pregnancy did not adversely affect the outcomes of infants $(13,18,19)$. However, a further study with a larger population and longer research period is required to confirm the effects of antiviral treatment against HBV during pregnancy on maternal and infant outcomes.

\section{Conclusion}

In this prospective study, while the untreated group included inactive carriers, there were more patients at risk for perinatal transmission in the treated group. Although, receiving antiviral therapy can reduce viral load successfully, most pregnant women in whom treatments were withheld, experienced increased HBV DNA levels. Also, the postpartum hepatic flare was rare but occurred in both the treated and the untreated groups. When compared with the untreated group, we found that antiviral therapy in the treated group did not adversely affect the outcomes of infants. As a result, we successfully prevented MTCT by starting antiviral therapy if necessary and close monitoring of patients and administering active and passive immunoprophylaxis to newborns.

Acknowledgments: None

Conflict of Interest: The authors report no conflict of interest. Funding: This article is not financially supported by any organization.

Authors' contributions: All authors have participated suficiently in the study while managing the conception and design of the study, acquisition of data, analysis of data, drafting the manuscript.

\section{References}

1. Piratvisuth T. Optimal management of HBV infection during pregnancy. Liver Int. 2013;33 Suppl 1:188-94. 
Doi: 10.1111/liv.12060.

2. Kubo A, Schlager L, Marks AR, Laktriz D, Beumout C, Gabellini K, et al. Prevention of vertical transmission of hepatitis B: an observational study. Ann Intern Med. 2014;160(12):828-35. Doi:10.7326/M13-2529.

3. Terrault NA, Bzowej NH, Chang KM, Hwang JP, Jonas MM, Murad MH, et al. AASLD guidelines for treatment of chronic hepatitis B. Hepatology. 2016;63(1):261-83. Doi: 10.1002/hep.28156.

4. European Association for the Study of the Liver. EASL 2017 Clinical Practice Guidelines on the management of hepatitis B virus infection. J Hepatol. 2017;67(2):370-98. Doi: 10.1016/j.jhep.2017.03.021.

5. Dunkelberg JC, Berkley EM, Thiel KW, Leslie KK. Hepatitis B and C in pregnancy: a review and recommendations for care. J Perinatol. 2014;34(12):882-91. Doi:10. 1038/jp.2014.167.

6. Hou J, Liu Z, Gu F. Epidemiology and prevention of hepatitis B virus infection. Int J Med Sci. 2005;2(1):50-7. Doi: 10.7150/ijms.2.50.

7. Zou H, Chen Y, Duan Z, Zhang H, Pan C. Virologic factors associated with failure to passive-active immunoprophylaxis in infants born to HBsAg-positive mothers. J Viral Hepat. 2012;19(2):e18-e25. Doi:10.1111/j.13652893.2011.01492.x.

8. Bzowej NH. Optimal management of the Hepatitis B patient who desires pregnancy or is pregnant. Curr Hepat Rep. 2012;11(2):82-89. Doi:10.1007/s11901-012-0130-X.

9. Cui AM, Cheng XY, Shao JG, Li HB3, Wang XL, Shen $\mathrm{Y}$, et al. Maternal hepatitis B virus carrier status and pregnancy outcomes: a prospective cohort study. BMC pregnancy childbirth. 2016;16:87. Doi:10.1186/s12884-0160884-1.

10. Chen JZ, Liao ZW, Huang FL, Su RK, Wang WB, Cheng $\mathrm{XY}$, et al. Efficacy and safety of tenofovir disoproxil fumarate in preventing vertical transmission of hepatitis B in pregnancies with high viral load. Sci Rep. 2017;7 (1):4132. Doi:10.1038/s41598-017-04479-X.

11. Greenup AJ, Tan PK, Nguyen V, Glass A, Davison S, Chatterjee U, et al. Efficacy and safety of tenofovir diso- proxil fumarate in pregnancy to prevent perinatal transmission of hepatitis B virus. J Hepatol. 2014;61(3):502-7. Doi:10.1016/j.jhep.2014.04.038.

12. Nurutdinova D, Onen NF, Hayes E, Mondy K, Overton ET. Adverse effects of tenofovir use in HIV-infected pregnant women and their infants. Ann Pharmacother. 2008;42(11):1581-5. Doi: 10.1345/aph.1L083.

13. Yi P, Chen R, Huang Y, Zhou RR, Fan XG. Management of mother-to-child transmission of hepatitis $\mathrm{B}$ virus: Propositions and challenges. J Clin Virol. 2016;77:32-9. Doi:10.1016/j.jcv.2016.02.003.

14. Pan CQ, Lee HM. Antiviral therapy for chronic hepatitis B in pregnancy. Semin Liver Dis. 2013;33(2):138-46. Doi:10.1055/s-0033-1345718.

15. Kim HY, Choi JY, Park CH, Jang JW, Kim CW, Bae SH, et al. Outcome after discontinuing antiviral agents during pregnancy in women infected with hepatitis B virus. J Clin Virol. 2013;56(4):299-305. Doi:10.1016/j.jcv. 2012.11.019.

16. Elefsiniotis I, Vezali E, Vrachatis D, Hatzianastasiou S, Pappas S, Farmakidis G, et al. Post-partum reactivation of chronic hepatitis B virus infection among hepatitis B eantigen-negative women. World J Gastroenterol. 2015; 21(4):1261-7. Doi:10.3748/wjg.v21.i4.1261.

17. Unal C, Tanacan A, Ziyadova G, Fadiloglu E, Beksac M. Effect of viral load on pregnancy outcomes in chronic hepatitis B infection. J Obstet Gynaecol Res. 2019;45(9): 1837-1842. Doi: 10.1111/jog.14065.

18. Tan Z, Yin Y, Zhou J, Wu L, Xu C, Hou H.. Telbivudine treatment of hepatitis $\mathrm{B}$ virus-infected pregnant women at different gestational stages for the prevention of motherto-child transmission: Outcomes of telbivudine treatment during pregnancy. Medicine (Baltimore). 2016;95(40): e4847. Doi:10.1097/MD.0000000000004847.

19. Pintye J, Baeten JM, Celum C, Mugo N, Ngure K, Were E, et al. Maternal Tenofovir Disoproxil Fumarate use during pregnancy is not associated with adverse perinatal outcomes among HIV-infected East African women: A prospective study. J Infect Dis. 2017;216(12):1561-8. Doi:10.1093/infdis/jix542. 